\title{
MARCEL NICOLAS MULLER, Les voix narratives dans "La Recherche du temps perdu"
}

\section{Chiara Nifosi}

\section{OpenEdition}

\section{Journals}

\section{Edizione digitale}

URL: https://journals.openedition.org/studifrancesi/44163

DOI: 10.4000/studifrancesi.44163

ISSN: 2421-5856

\section{Editore}

Rosenberg \& Sellier

\section{Edizione cartacea}

Data di pubblicazione: 1 juin 2021

Paginazione: 239-240

ISSN: 0039-2944

\section{Notizia bibliografica digitale}

Chiara Nifosi, «MARCEL niColas mulleR, Les voix narratives dans "La Recherche du temps perdu"», Studi Francesi [Online], 193 (LXV | I) | 2021, online dal 01 juillet 2021, consultato il 15 octobre 2022. URL: http://journals.openedition.org/studifrancesi/44163 ; DOI: https://doi.org/10.4000/studifrancesi. 44163

Questo documento è stato generato automaticamente il 15 octobre 2022.

\section{(c) (i) (9)}

Creative Commons - Attribuzione - Non commerciale - Non opere derivate 4.0 Internazionale - CC BY NC-ND 4.0

https://creativecommons.org/licenses/by-nc-nd/4.0/ 


\title{
MARCEL NICOLAS MULLER, LeS Voix narratives dans "La Recherche du temps perdu"
}

\author{
Chiara Nifosi
}

\section{NOTIZIA}

MARCEL NICOLAS MULLER, Les voix narratives dans "La Recherche du temps perdu", Genève, Librairie Droz, 2019, «Courant critique» 2, 224 pp.

1 Il presente volume è la riedizione del celebre saggio critico di Marcel Muller del 1965, pubblicato all'epoca sempre da Droz. Questa volta, tuttavia, il testo di Muller si arricchisce di una premessa inedita di Geneviève Henrot Sostero, curatrice discreta di un volume che viene sostanzialmente lasciato intatto rispetto all'edizione originale, ad eccezione dell'aggiornamento dei riferimenti alla versione della Pléiade del 1987-89 ad opera di Jean-Yves Tadié. Introdotto da Henrot Sostero come un intellettuale di stampo classico, tanto in campo filologico quanto filosofico, Muller ha il merito di scandagliare la Recherche per offrire delle risposte - che lui stesso definisce insoddisfacenti nella sua conclusione (p. 215) - ad una delle domande più complesse poste dal testo proustiano: chi prende la parola all'interno della narrazione? A quali identità corrisponde l'io che parla ai suoi lettori?

2 L'analisi di Muller si divide in tre parti, che seguono una breve introduzione volta a problematizzare l'identità del «Je», soggetto grammaticale dietro al quale si cela una molteplicità di persone differenti (p. 19), e a ricostruire il dibattito scientifico sviluppatosi attorno alla di certo spinosa questione. Percorrendo lavori di Germaine Brée, Jean-Paul Sartre, Michihiko Suzuki e molti altri, Muller riesce ad aprire uno spazio di riflessione personale in cui gli è possibile articolare la ripartizione della voce narrativa nella Recherche in sette soggetti (p. 34). Muller è consapevole delle ripercussioni filosofiche di tale discorso: uscire dalla finzione - ovvero dalla 
soggettività assoluta del protagonista, mera creazione finzionale - implica l'ingresso in un terreno più tradizionale, quello di un soggetto onnisciente ed esterno alla finzione stessa. È attorno a questa contraddizione che si sviluppa l'argomentazione del saggio.

3 La prima parte del libro è dedicata alle diverse sfaccettature di quello che abbiamo appena chiamato il Protagoniste, che a sua volta si incarna nelle tre figure dell'Héros, del Narrateur e del Sujet intermédiaire. L'Héros (Héros-Je e Héros-Nous) è come sospeso tra i poli di due antinomie, quelle di individuo vs. gruppo e di eternità vs. tempo (p. 45), in particolare durante l'infanzia, dove tali tensioni si manifestano proprio nelle attività solitarie, come la masturbazione, e nella socialità, come nell'episodio della visita di Swann. Il rapporto dell'Héros con il Narrateur è descritto da Muller come asintotico, in quanto i due tendono ad avvicinarsi senza mai sovrapporsi del tutto (p. 69). A negoziare lo scambio di informazioni tra i due vi è il Sujet intermédiaire, il cui compito è quello di trasmettere i ricordi da una posizione ancora inconsapevole dal punto di vista letterario (p. 53).

4 La seconda parte si concentra sulla distinzione fra Écrivain e Romancier, categorie atte a rimarcare una presenza autoriale, non più puramente soggettiva, nel tessuto testuale $\mathrm{e}$ narratologico del romanzo. Se l'Écrivain è colui che a stento trattiene la gioia della creazione attraverso delle soluzioni stilistiche che vanno dall'aggettivazione all'humour, il Romancier si rivela grazie al carattere onnisciente dei suoi interventi: la sua voce si spinge infatti là dove non può in alcun modo arrivare l'esperienza del Protagoniste, tanto da suggerire un parallelismo con Balzac (p. 140). Nella terza parte, infine, più breve delle altre, si delinea la figura del Signataire, la cui voce introduce nell'opera elementi di cui Muller mostra un riscontro extra-testuale, in lettere e saggi che offrono una chiave di lettura a personaggi e temi della Recherche. Il Signataire è dunque colui che si approssima maggiormente allo stesso Marcel Proust.

5 Il testo di Muller non smette di offrire una prospettiva convincente sulle sfumature della separazione, ormai assodata eppure ancora problematica, tra il narratore Marcel e l'autore Proust, suggerendo inoltre con estrema sensibilità critica i possibili sviluppi di questo tema grazie al supporto della genetica testuale, che nei decenni successivi ha trovato ampio riscontro presso i ricercatori proustiani, in particolare in seno all'ITEM di Parigi. 